\title{
PRE-SERVICE PHYSICAL EDUCATION TEACHERS' KNOWLEDGE OF APPROPRIATE INSTRUCTIONAL PRACTICES IN SECONDARY SCHOOL PHYSICAL EDUCATION
}

\author{
David Barney and Robert Christenson \\ Oklahoma State University, the United States of America \\ Frank Pleban \\ Grand Valley State University, the United States of America
}

\begin{abstract}
Secondary school can serve as a time for youth to prepare themselves for the 'real world', and physical education can play an important role in this preparation. Yet in the past, secondary school physical education has not been very effective in preparing youth for life after secondary school. One area to help improve secondary school physical education is in the preparation of pre-service physical education teachers. It is during the preparation of pre-service physical education teachers that they will be taught and trained regarding appropriate instructional practices in secondary school physical education. The National Association of Sport and Physical Education created a document regarding appropriate educational practices in secondary school physical education. For this study, a survey was adapted from the National Association of Sport and Physical Education appropriate instructional practice document. Three hundred and thirteen pre-service physical education teachers from seven institutions of higher education throughout the United States were surveyed regarding their knowledge of appropriate instructional practices in secondary school physical education. It was found that pre-service physical education teachers inappropriately answered six of the 18 survey statements (33\%) regarding appropriate instructional practices in secondary school physical education. When pre-service physical education teachers graduate and expose secondary school pupils to appropriate practices, there is a better chance the pupils will be prepared for the 'real world'.
\end{abstract}

Key words: pre-service physical education teachers, instructional practices, secondary school physical education

\section{Introduction}

For youth, the secondary school experience serves as a leaping off point into full-fledged adulthood. Many youths are seeking more independence from their parents and families, looking forward to attending college or starting a career (Rollins, 1999). For these reasons 
and many others, secondary school pupils want their secondary school education to be meaningful and to better prepare them for life after school (Petersen, 1998). Therefore, teachers educating secondary school pupils need help in preparing the latter for the 'real world'. Secondary school physical education programmes have the opportunity to help pupils achieve individual success, physical fitness, exploration, self-testing, monitoring, continued physical skill development, wellness concepts, choice and preparation for a lifetime of physical activity (Pangrazi, 2003). Pangrazi (2003) continues by saying that "the high school years should be a time of mastery ... depth of learning, performance, and competency should be key outcomes. A key measure of accomplishment would be that pupils could interface into an adult setting and feel comfortable" (p. 114).

Literature has revealed that secondary school physical education has fallen short in helping secondary school pupils prepare for life after secondary school (Ennis, 1995). Literature indicates that, for secondary school physical education to be relevant for youth, the curriculum and the opportunity for the youth to choose the activities they participate in can strongly impact their attitudes towards being physically active later in life (Smith \& St. Pierre, 2009). Other research in the literature looked at the physical education curriculum in an urban secondary school physical education programme and the influence it had on secondary school pupils' non-compliant behaviour during physical education classes. In this study, it was discovered that pupils did not participate in class activities, sat in the bleachers during activities, would roam around the gymnasium, walk around the track, slowly retrieve a ball or just not dress for class activities. The other important aspect in secondary school physical education affecting pupils is having the chance to help decide the types of activities they participate in during class time. It was concluded that secondary school physical education teachers need to make changes in the curriculum that pupils will find relevant. The best way to do this is getting pupils' input in the types of activities they will participate in for the purpose of exposing pupils to lifelong physical education, such as swimming, golf and tennis (Ennis, 1995).

Courturier, Chepko and Coughlin (2005) studied primary and secondary school pupils' responses to their physical education classes. Pupils were surveyed regarding many aspects of their physical education experience, including course curriculum. Some of their responses were, "I would like to be able to pick my own activities", "I would like to be able to tell the teacher the activities I would like to do", "I would like to choose what group of students I participate with" and "I would like to be able to work at my own pace".

In general, secondary school physical education has been portrayed in a negative light. To a certain point, secondary school physical education teachers are adding to this negative experience for pupils in regards to their participation in physical education and in physical activity later in life, thus affecting their health throughout their lives.

One way to positively promote secondary school physical education is in the preparation of pre-service physical education teachers. It is during the pre-service physical education teachers' studies that they are taught proper instructional methods of how to create unit/ lesson plans, give appropriate feedback, organisational methods, such as creating and execut- 
ing classroom management and practical experiences, such as the practicum and students' teaching experiences. With this stated, pre-service physical education teacher educators have a great responsibility in preparing pre-service teachers for their first years of teaching secondary school physical education classes.

It may be asked why pre-service physical education teachers' educators have such a great responsibility in preparing novice teachers for their first years of teaching. Research suggests that pre-service physical education teachers begin their training with well-formed beliefs about teaching, developed through many years of schooling (Placek, Dodds, Doolittle, Portman, Ratliffe, \& Pinkham, 1995). However, many of the pre-service physical education teachers have been exposed to inappropriate instructional practices while they were pupils themselves in secondary school. Two examples of inappropriate instructional practices pupils may have been exposed to were having captains pick teams in front of the whole class or having pupils do strenuous exercises as punishment for bad behaviour during a lesson. These examples and others are some types of inappropriate instructional practices pre-service teachers may bring with them when they enter their university study courses.

One tool pre-service physical education teachers' educators can use is the document titled “Appropriate Instructional Practice Guidelines for High School Physical Education” published in 2009 by the National Association for Sport and Physical Education (NASPE, 2009). One of the main purposes of the document is to "address key aspects of instructional strategies and practices that are essential to delivery of quality physical education to adolescents and young adults" (p. 3). Another purpose of this document is to provide specific guidelines that identify practices that are in the best interest of secondary school pupils. This document was written for physical education teachers along with parents and school administrators. It is a logical starting point for educating pre-service physical education teachers regarding appropriate instructional practices in secondary school physical education (Barney \& Strand, 2008). For this reason, the purpose of this study was to gain knowledge of what pre-service physical education teachers currently know regarding appropriate instructional practices in secondary physical education.

\section{Methods}

\section{Participants}

Participants for this study were 313 pre-service physical education teachers (161 males and 162 females) from seven universities, three located in the south and four located west of the Rocky Mountains. These participants were all enrolled in the Introduction to Physical Education course, or one similar to it, at their respective universities. This particular population was utilised for this study as the Introduction to Physical Education course is typically one of the first courses pre-service physical education teachers take as they begin their sequence of study. Prior to this course pupils have not generally been exposed to appropriate instructional practices in physical education which could affect their understanding regarding the appro- 
priate or inappropriate teaching techniques in secondary school physical education.

\section{Instrumentation}

For this study, the researchers utilised a survey that was created and used from another study investigating secondary school pupils' knowledge of appropriate instructional practices in secondary school physical education (Barney \& Strand, 2008). The High School Physical Education Appropriate Practice Survey (HSPEAPS) is an 18-statement survey constructed to measure appropriate and inappropriate instructional practices in secondary school physical education. The HSPEAPS is constructed of four general areas: 1) curriculum; 2) learning environment; 3 ) instructional strategies and 4) assessment. Five statements referring to curriculum, four to the learning environment, five to instructional strategies and four to assessment, for a total of 18 statements on the survey.

\section{Procedures}

For this study, the researchers contacted pre-service physical education teacher training and education faculty at seven different higher education institutions. A total of seven pre-service physical education teachers' training and education faculty members (six males and one female), averaging ten years in higher education experience, agreed to have their students voluntarily participate in this study. The researchers contacted each faculty member by phone and explained the purpose and procedures of the study. Students not voluntarily participating in the study were assured that non-participation or withdrawal from this study would not negatively affect their mark in their Introduction to Physical Education class or class standing. After the surveys were completed, the faculty member mailed the surveys back to the researchers. Results for this study are reported as percentages. The university Institutional Review Board (IRB) granted approval to conduct this study.

\section{Results}

For the results of this study, the four general areas from the survey will be discussed.

\section{Curriculum}

The curriculum data had one statement (statement five) that was inappropriately answered by both male and female pre-service physical education teachers. It states: The fitness component of secondary school physical education should consist of mass exercise following a designated leader. For this statement, $63 \%$ of the male pre-service physical education teachers felt this is an appropriate instructional practice, and $45 \%$ of the female pre-service physical education teachers felt the same.

When looking at the institutional data, four institutions (institutions two, three, six and seven) felt that the fitness component of secondary school physical education should consist 
of mass exercise following a designated leader was appropriate.

\section{Learning environment}

The data from statements regarding the learning environment found one statement (statement seven) that was inappropriately answered by pre-service physical education teachers. It states: One method for teachers to implement social interaction among pupils is to let them randomly select teams for activities. For this statement, $61 \%$ of the male pre-service physical education teachers and $53 \%$ of the female pre-service physical education teachers inappropriately answered this statement.

For the institutions, four of the seven institutions inappropriately answered statement seven. Institution two (76\%), institution three (65\%), institution six (71\%) and institution seven $(62 \%)$ felt this practice was appropriate for secondary school physical education. Interestingly, institution four (46\%) and institution five (42\%) also felt this practice was appropriate.

\section{Instructional strategies}

Data from the instructional strategies statements identified one statement that was inappropriately answered by pre-service physical education teachers. Statement 12 states: Teachers should have students warm-up on their own before the class activities begin. The data reveals that $51 \%$ of the male pre-service physical education teachers inappropriately answered this statement.

One institution also inappropriately answered statement 12 . Pre-service physical education teachers from institution two (52\%) inappropriately answered the statement.

\section{Assessment}

An assessment statement that was inappropriately answered by pre-service physical education teachers states: Part of a student's mark should be based on attendance, dressing for activity and compliance to classroom rules. The data showed that $90 \%$ of the male pre-service physical education teachers and $93 \%$ of the female pre-service physical education teachers inappropriately answered this statement. For statement 18, which states: Because secondary school students are more skilled, tests should be based on a summative (final) evaluation for each unit during the term, $60 \%$ of the male pre-service physical education teachers and $54 \%$ of the female preservice physical education teachers provided inappropriate answers.

Finally, the data for the assessment statements found three statements inappropriately answered. For statement 15, one institution (institution two) inappropriately answered this statement (52\%). It states: Because of secondary school students' level of skills, general feedback is all that is needed for students regarding performance in class. A second statement that was inappropriately answered by all seven institutions was statement 17, which states: Part of a student's mark should be based on attendance, dressing for activity and compliance to classroom rules. The percentage of incorrect answers ranges from $78 \%$ to $100 \%$. The third statement that 
was inappropriately answered by the institutions was statement 18 , which states: Because secondary school students are more skilled, tests should be based on a summative (final) evaluation for each unit during the term. Five institutions (two, three, five, six and seven) inappropriately answered this statement. The range of percentages that were inappropriately answered was from $53 \%$ to $78 \%$.

\section{Discussion}

The purpose of this study was to gain knowledge of what pre-service physical education teachers know regarding appropriate instructional practices in secondary school physical education. The findings indicate that pre-service physical education teachers tended to correctly identify appropriate instructional practices in secondary school physical education. Yet, there are a couple of topics from the data that should be addressed.

One of the first items pre-service physical education teachers inappropriately answered dealt with the fitness component of secondary school physical education consisting of mass exercises following a designated leader. For many years, physical education teachers have used this method of teaching a fitness component. Whatever the fitness component is being taught, it should provide a focus for fitness activities. When teaching a certain activity, this should provide the physical educator with an opportunity to teach and emphasise the fitness component that can be gained when using the particular skill (NASPE, 2009).

Another point to be addressed from statement seven claims: One method for teachers to implement social interaction among students is to let students randomly select teams for activities. Hastie (2003) has developed a novel method of selecting teams. He (Hastie, 2003) suggests that captains are selected, who then, in private, select even teams. However, a key aspect of this format is that the captain themselves are assigned to teams through a lottery; that is, when the captains select the original teams, they themselves do not know which of those teams they will become a member of. This method of team selection tends not to embarrass pupils. Additionally, other scholars have made similar suggestions when putting pupils on teams or in groups (Rink, 2002; Darst \& Pangrazi, 2009).

Another point of discussion deals with primarily grading a student-based on their attendance, dressing for activity and compliance to classroom rules. The researchers were surprised to find that over $90 \%$ of both male and female pre-service physical education teachers and over $78 \%$ of the pre-service physical education teachers from the seven institutions inappropriately answered this statement. Barney and Strand (2008) commented that there is a certain mindset among pre-service physical education teachers' educators, that this is the primary way a learner can earn a passing mark in a physical education class. This belief is easy to understand, as for many years pre-service physical education teachers' educators have used this specific criterion to grade pupils. Due to this practice, the practicality of physical education classes has and is being questioned by parents and administrators. Miller (2002) states that basing marks on dress, attendance and effort undermines physical education and the true purpose of a physical education class. Pre-service physical education teachers' educators need 
to explore a variety of assessment techniques to analyse pupils' understanding of their learning in physical education lessons (Barney \& Strand, 2006).

One last point of discussion is a majority of the male (60\%) and female (54\%) pre-service physical education teachers felt that secondary school pupils are more skilled in class activities, thus tests should be based on a summative (final) evaluation for each unit during the term. Also, five institutions (two, three, six and seven) inappropriately answered this statement (ranging between 53\% to 78\%). There is nothing wrong with summative assessments; however, formative assessments have been found to be beneficial for pupils' learning. Miller (2006) stated that formative assessments allow the teacher the opportunity to diagnose learning problems and prescribe the necessary changes for the pupil. Miller (2006) continues by stating that "formative assessments can serve to motivate pupils to achieve the learning goals" (p. 82). Using formative assessments is one method secondary school physical education teachers can use in providing a positive and successful experience for the pupil. Pangrazi (2004) has said physical education teachers must provide a positive learning experience that encourages repetition and refinement. This allows opportunities to succeed in the learning process, doing the work it takes to become more skilled.

\section{Conclusions}

Why is it so important that pre-service physical education teachers know and understand what instructional practices are appropriate and inappropriate to use and implement in their teaching of secondary school physical education? When pre-service physical education teachers are aware of appropriate instructional practices in secondary school physical education, the beneficiaries of appropriate instructional practices will be the pupils. After leaving secondary school, youngsters will be going into the 'real world'. Teachers exposing their pupils to appropriate curriculum, providing an appropriate learning environment, teaching appropriate instructional strategies and giving appropriate assessments will help pupils interface into an adult setting successfully and comfortably. Pre-service physical education teachers' preparation faculty have to be vigilant in their preparation of pre-service physical education teachers to educate, train and demonstrate what practices are appropriate for secondary school physical education. As stated previously, many pre-service physical education teachers enter their university with many years of exposure to inappropriate practices in physical education. Thus, in their minds, many of those inappropriate instructional practices they have been exposed to are considered the right or correct way of teaching physical education. As pre-service physical education teachers become in-service teachers at secondary school, they have a great opportunity to affect pupils' attitudes in a positive direction. When these secondary school pupils mature, they will assume the role of a voter, a parent, a school board member and a politician, making important decisions concerning physical education in schools (Aicinena, 1991). For this reason, pre-service physical education teachers that become secondary school physical education teachers need to seriously think about the importance of their classes being guided by appropriate instructional practices (Barney \& Strand, 2008). 
Another conclusion from this study that has application to other fields in teacher education and education in general is the importance of exposing pre-service teachers to appropriate instructional practices in the classroom. Even though the context of this study was in physical education, teacher educators in other fields need to be mindful of their preparation of pre-service teachers. As previously stated, novice teachers will teach their classes how they were taught as pupils. In many cases, the instructional practices were not appropriate. For this reason, pre-service teachers' educators need to properly demonstrate and explain appropriate instructional practices that should be used in the classroom.

\section{References:}

Aicinena, S. (1991). The teacher and student attitudes toward physical education. The Physical Educator, 48, 28-32.

Barney, D., \& Strand, B. (2006). Appropriate practices in elementary physical education: Creating a foundation for physical education majors. Teaching Elementary Physical Education, 17(5), 20-23.

Barney, D., \& Strand, B. (2008). Do high school students know what practices are appropriate in physical education. The High School Journal, 92(1), 33-39.

Couturier, L. E., Chepko, S., \& Coughlin, M. A. (2005). Student voices - what middle and high school students have to say about physical education. The Physical Educator, 62, 170-177.

Darst, P. W., \& Pangrazi, R. P. (2009). Dynamic physical education for secondary school students (6th ed.). San Francisco, CA: Pearson Benjamin Cummings.

Ennis, C. D. (1995). Teachers' responses to noncompliant students: The realities and consequences of a negotiated curriculum. Teaching \& Teacher Education, 11, 445-460.

Hastie, P. (2003). Teaching for lifetime physical activity through quality high school physical education. San Francisco, CA: Benjamin Cummings.

Miller, D. K. (2002). Measurement by the physical educator: Why and how. Boston, MA: McGraw-Hill.

Miller, D. K. (2006). Measurement by the physical educator: Why and how (5th ed.). Boston, MA: McGraw-Hill.

National Association for Sport and Physical Education. (2009). Appropriate instructional practices guidelines for high school physical education. Reston, VA: Author.

Pangrazi, R. P. (2003). Physical education k-12: “All for one and one for all”. Quest, 55, 105117.

Pangrazi, R. P. (2004). Dynamic physical education for elementary school children (14th ed.). San Francisco, CA: Benjamin Cummings.

Placek, J. H., Dodds, P., Doolittle, S. A., Portman, P. A., Ratliffe, T. A., \& Pinkham, K. M. (1995). Teaching recruits' physical education backgrounds and beliefs about purposes of 
their subject matter. Journal of Teaching in Physical Education, 14, 246-261.

Petersen, A. C. (1998). Adolescent development. Annual Review of Psychology, 39, 583-607.

Rink, J. E. (2002). Teaching physical education for learning. Boston, MA: McGraw-Hill.

Rollins, L. (1999). Twentieth-century culture by the decades. Westport, CT: Greenwood Press.

Smith, M. A., \& St. Pierre, P. E. (2009). Secondary students' perceptions of enjoyment in physical education: An American and English perspective. The Physical Educator, 66, 4 209-221.

\section{Correspondence:}

David Barney, Ed. D., Oklahoma State University, 187 Colvin Center, Stillwater, OK 74078. Email: david.barney@okstate.edu 